\title{
A Review of Nail Changes in Acrokeratosis Paraneoplastica (Bazex Syndrome)
}

\author{
Bipasha Roy $^{a}$ Shari R. Lipner ${ }^{b}$ \\ ${ }^{a}$ New York Medical College School of Medicine, Valhalla, NY, USA; ${ }^{b}$ Department of Dermatology, Weill Cornell \\ Medicine, New York, NY, USA
}

\section{Keywords}

Acrokeratosis paraneoplastica - Bazex syndrome - Nails . Malignancy · Onychodystrophy · Squamous cell carcinoma

\section{Abstract}

Acrokeratosis paraneoplastica (Bazex syndrome) is a rare paraneoplastic dermatosis associated with internal malignancies. Clinical presentation is characterized by erythematous or violaceous scaly plaques involving the digits, nose, ears, palms, and soles. Nail changes commonly present concurrently with cutaneous manifestations. In this review, we characterize nail changes associated with acrokeratosis paraneoplastica. A total of 48 cases were analyzed. Nail findings were nonspecific, with the most common being nail plate thickening, onycholysis, subungual hyperkeratosis, longitudinal ridging, discoloration, and nail plate loss. In most patients, nail changes involved the majority of fingernails and toenails and most often appeared prior to the diagnosis of malignancy. The most common associated underlying malignancies were squamous cell carcinomas of the head and neck. A diagnosis of acrokeratosis paraneoplastica should be considered in patients with onychodystrophy in-

karger@karger.com www.karger.com/sad

Karger"

GOPEN ACCESS
(C) 2021 The Author(s)

Published by S. Karger AG, Basel

This is an Open Access article licensed under the Creative Commons Attribution-NonCommercial-4.0 International License (CC BY-NC) (http://www.karger.com/Services/OpenAccessLicense), applicable to the online version of the article only. Usage and distribution for commercial purposes requires written permission. volving multiple nails with accompanying atypical psoriasiform dermatoses. Screening for internal malignancies may significantly decrease morbidity and mortality for these patients.

(C) 2021 The Author(s)

Published by S. Karger AG, Basel

\section{Introduction}

Bazex' acrokeratosis paraneoplastica is a rare dermatological condition characterized by erythematous and hyperkeratotic plaques, involving the nose, ears, palm, and soles. Bazex syndrome is associated with internal malignancies, commonly of the upper aerodigestive tract [13]. Cutaneous manifestations commonly appear prior to cancer diagnosis and typically follow 3 distinct clinical stages. Nail dystrophy often presents during the first stage concurrently with papulosquamous plaques on the distal digits, nose, and ears [1,4]. Nail findings are common amongst acrokeratosis paraneoplastica patients [1]. Our objectives were to characterize nail changes associated with acrokeratosis paraneoplastica, which may be important clues to the presence of internal malignancies. 


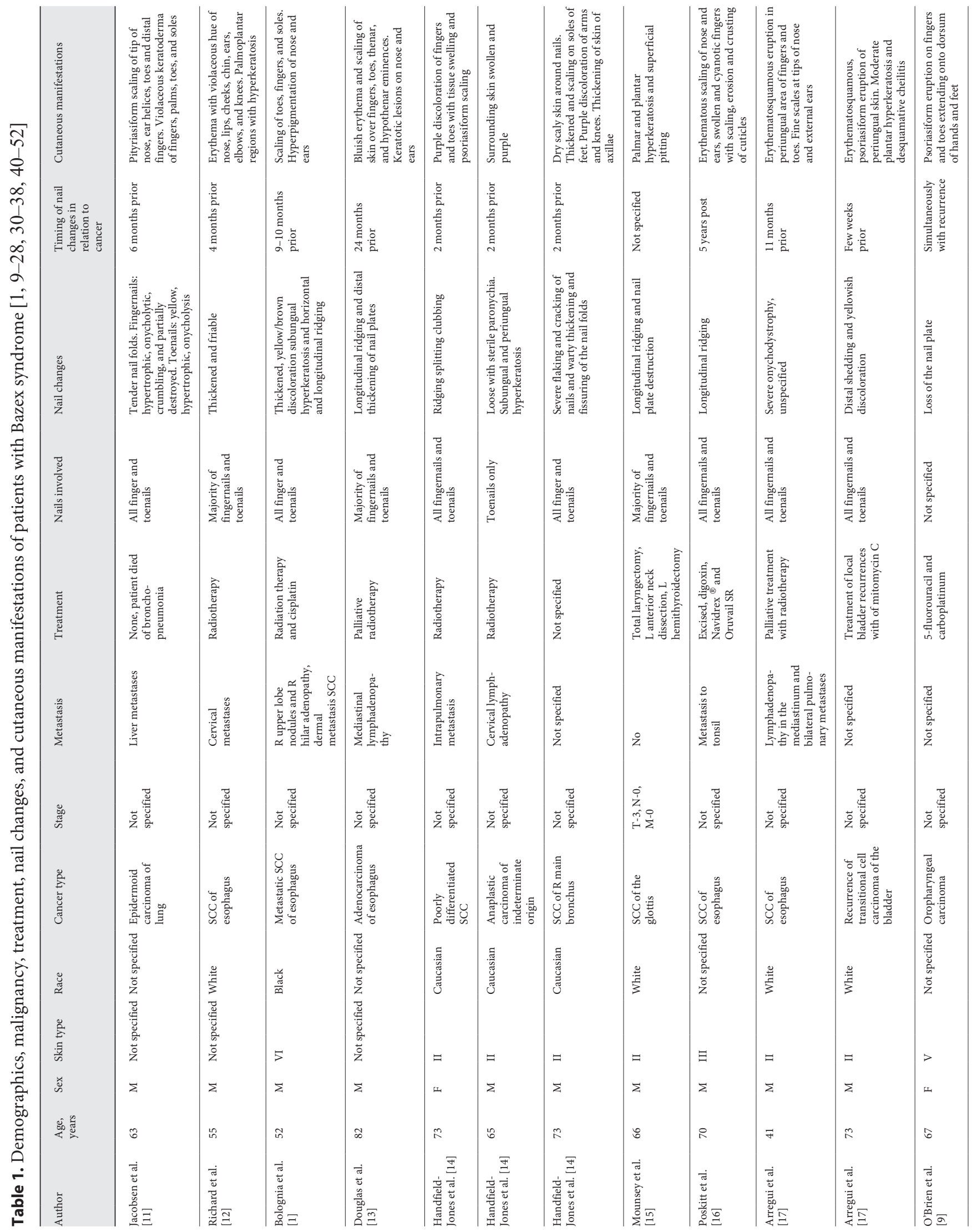




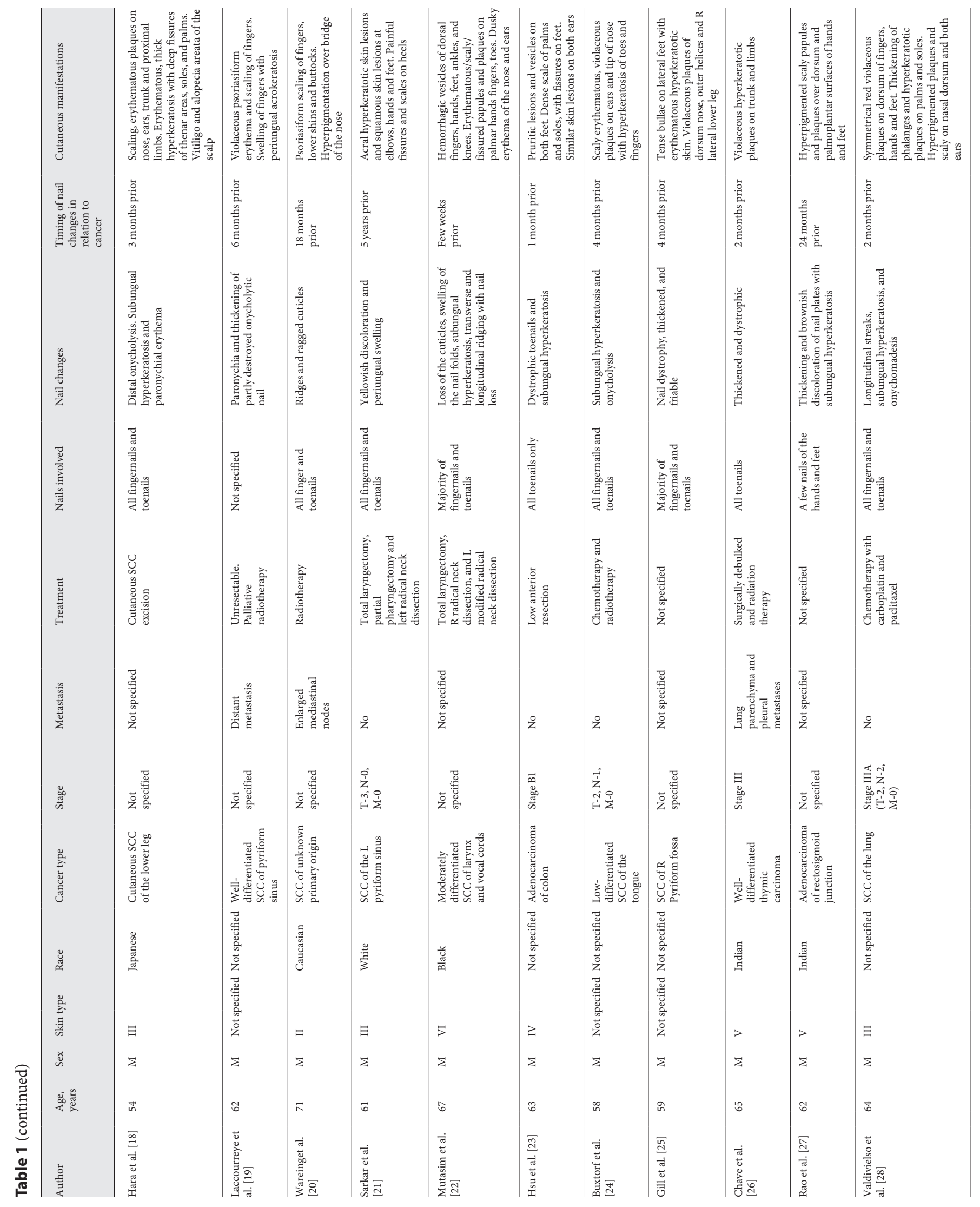




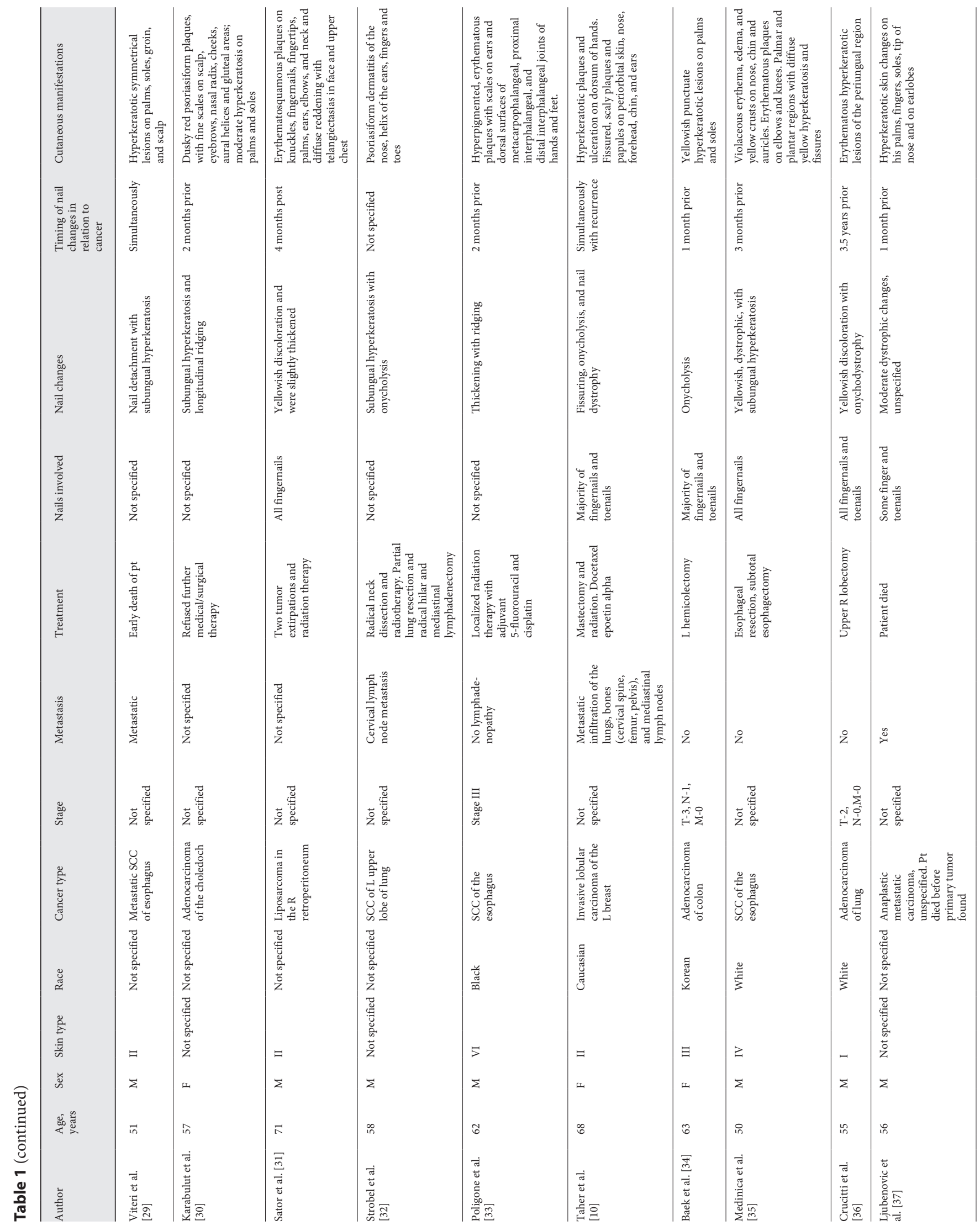




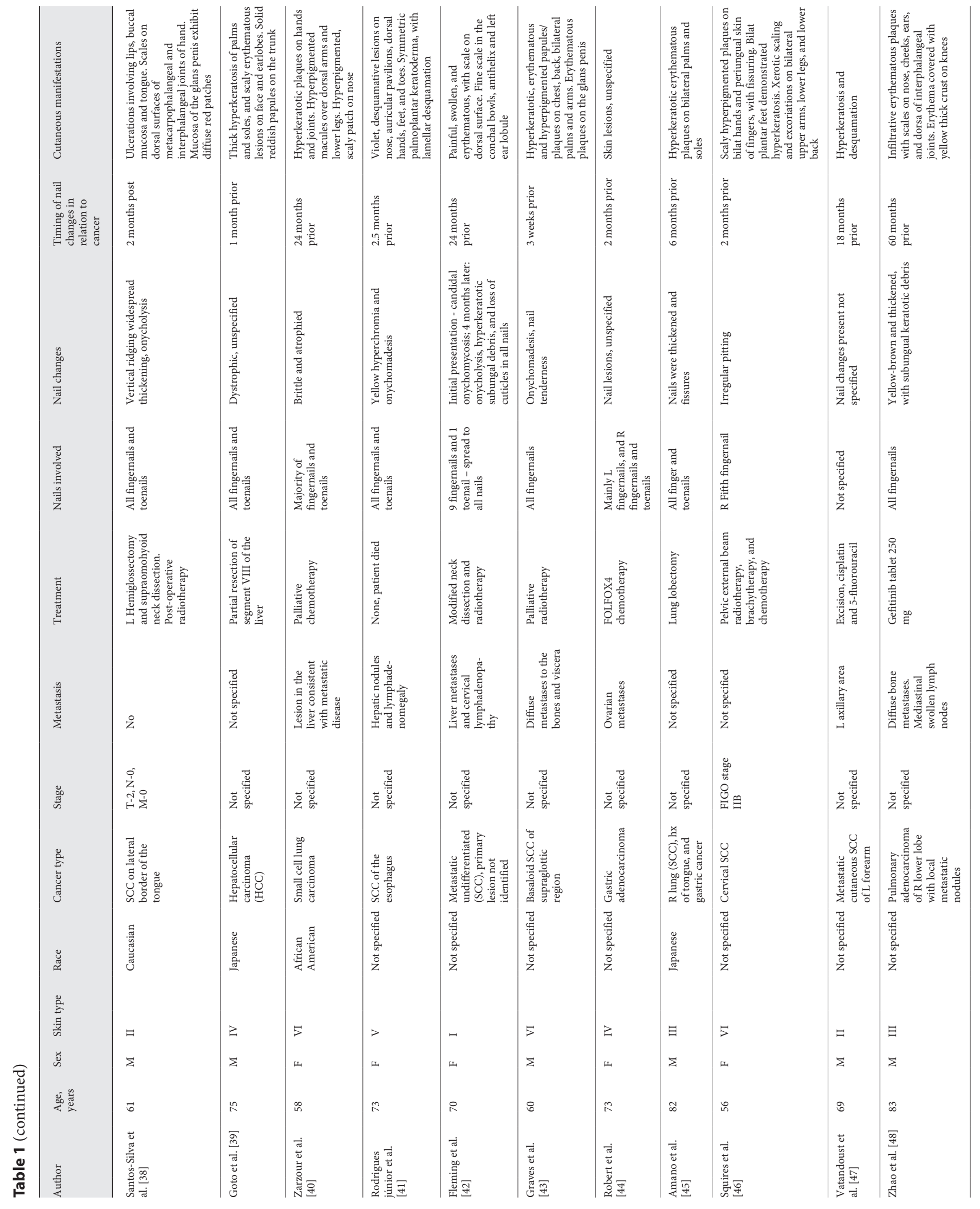




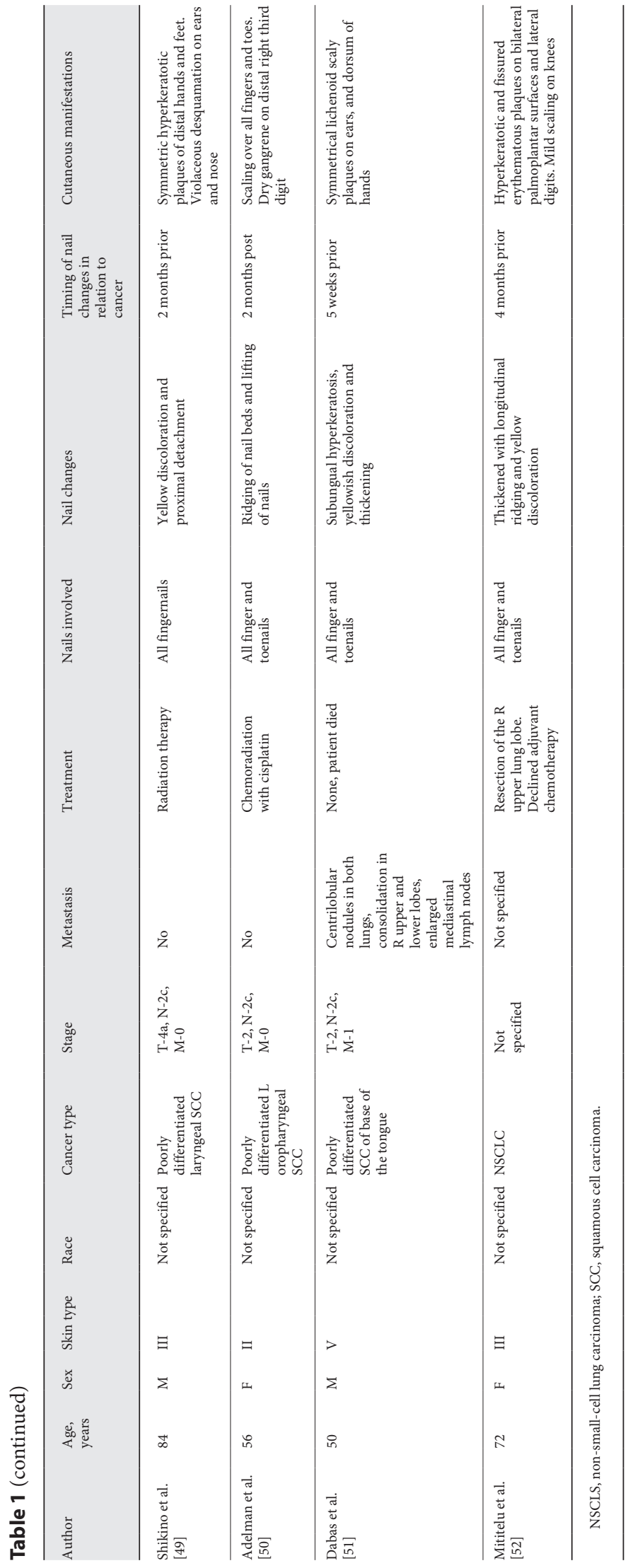

Table 2. Summary of primary cancer locations and types of in patients with Bazex syndrome

\begin{tabular}{|c|c|c|}
\hline Primary cancer: location and type & Cases & Percentage \\
\hline Carcinoma of head and neck region & 21 & 44 \\
\hline SCC of the esophagus & 8 & 38 \\
\hline SCC of the larynx and vocal cords & 4 & 19 \\
\hline SCC of the tongue & 3 & 14 \\
\hline SCC of pyriform sinus & 3 & 14 \\
\hline Oropharyngeal carcinoma & 2 & 10 \\
\hline Adenocarcinoma of the esophagus & 1 & 5 \\
\hline Carcinoma of the lung & 10 & 21 \\
\hline SCC & 6 & 60 \\
\hline Epidermoid carcinoma & 1 & 10 \\
\hline Adenocarcinoma & 1 & 10 \\
\hline Small-cell lung carcinoma & 1 & 10 \\
\hline NSCLC & 1 & 10 \\
\hline Gastrointestinal carcinoma & 6 & 12 \\
\hline Adenocarcinoma of Colon & 2 & 32 \\
\hline Gastric adenocarcinoma & 1 & 17 \\
\hline Adenocarcinoma of colon & 1 & 17 \\
\hline Adenocarcinoma of the choledoch & 1 & 17 \\
\hline $\begin{array}{l}\text { Adenocarcinoma of rectosigmoid junction } \\
\text { Hepatocellular carcinoma }\end{array}$ & 1 & 17 \\
\hline Genitourinary carcinoma & 2 & 4 \\
\hline Cervical SCC & 1 & 50 \\
\hline Transitional-cell carcinoma of bladder & 1 & 50 \\
\hline Cutaneous carcinoma & 2 & 4 \\
\hline SCC & 2 & 100 \\
\hline Carcinoma of breast & 1 & 2 \\
\hline Lobular carcinoma & 1 & 100 \\
\hline Sarcoma & 1 & 2 \\
\hline Liposarcoma of retroperitoneum & 1 & 100 \\
\hline Thymic carcinoma & 1 & 2 \\
\hline Indeterminate origin & 4 & 8 \\
\hline SCC & 2 & 50 \\
\hline Anaplastic carcinoma & 2 & 50 \\
\hline
\end{tabular}

SCC, squamous cell carcinoma; NSCLS, non-small-cell lung carcinoma.

\section{Methods}

The PubMed database was reviewed for the keywords "Bazex Syndrome and nail," "Acrokeratosis paraneoplastica and nail," "Acrokeratosis paraneoplastica," and "Bazex Syndrome." The search was limited to articles in the English language published between January 1, 1972, and July 15, 2020. In the initial search, 103 articles were identified and 36 were excluded because they did not pertain to acrokeratosis paraneoplastica, leaving 67 . Of the 67 remaining articles, 19 did not report any nail changes, leaving a total of 48 articles for final analysis. Cases were analyzed for age, gender, Fitzpatrick skin type, race, primary cancer type, cancer staging, presence of metastasis, cancer treatment, nails involved, nail clinical presentation, and cutaneous findings. Fitzpatrick skin type was determined by examining photos in the articles and using 
Table 3. Summary of nail findings in patients with Bazex syndrome

\begin{tabular}{lc}
\hline Nail changes & Percentage \\
\hline Thickening/onychauxis & 35 \\
Subungual hyperkeratosis & 31 \\
Yellow/brown discoloration & 27 \\
Onycholysis & 27 \\
Longitudinal ridging & 25 \\
Loss/destruction of nail plate & 13 \\
Fissuring & 8 \\
Onychomadesis & 6 \\
Paronychia & 6 \\
Horizontal ridging & 4 \\
Tenderness of nail & 4 \\
Crumbling/cracking & 4 \\
Loss of cuticles & 4 \\
Irregular pitting & 2 \\
Brittle & 2 \\
Atrophy & 2 \\
Candidal onychomycosis & 2 \\
Clubbing & 2 \\
Unspecified & 13 \\
\hline
\end{tabular}

the Fitzpatrick classification guidelines [5]. If photos or descriptions of the patient's skin type were unavailable or photos were black and white, they were recorded as not specified.

\section{Results}

There were 48 cases of acrokeratosis paraneoplastica with nail changes included in the final analysis. Demographics and case findings are shown in Table 1. Of these patients, $25 \%$ were female, with a mean age of 62.5 years (range 41-84 years). Fifteen patients (31\%) were classified as Fitzpatrick skin type I-II, 13 patients (27\%) as type III-IV, eleven (23\%) patients as type V-VI, and 9 patients (19\%) not specified. Eleven patients (23\%) were described as either Caucasian or White, 4 patients (8\%) African American or Black, 7 patients (14\%) Japanese, Korean, or Indian, and the races of 26 patients (55\%) were not specified.

Primary malignancies were most often localized to the head and neck region (42\%) and were most commonly squamous cell carcinomas (SCCs) of the esophagus. SCCs of the larynx, tongue, and oropharynx were also common forms of malignancies within the head and neck region. The lung was the second most common site of malignancy (21\%), with mostly SCCs (6 patients). Gastrointestinal carcinomas represented $12 \%$ of the cases, most commonly adenocarcinomas. Genitourinary, cutaneous, breast,

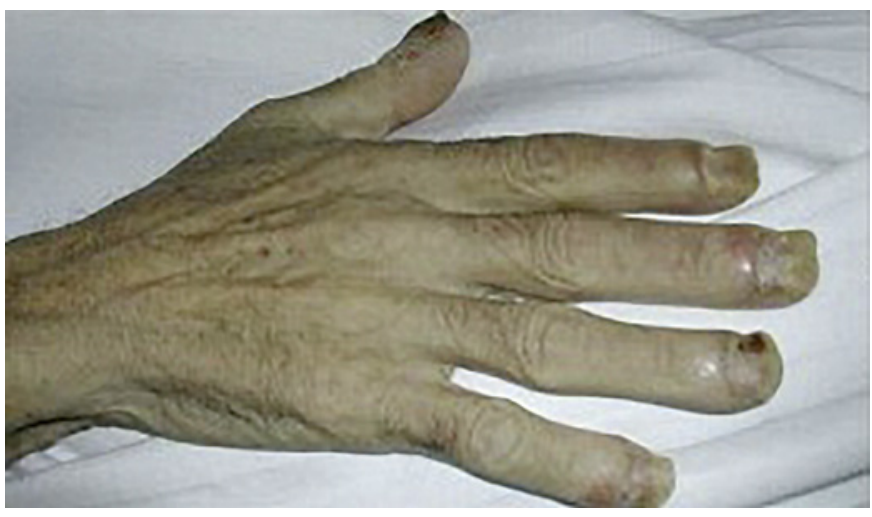

Fig. 1. Acrokeratosis paraneoplastica. Nail plate yellowing, onycholysis, and subungual hyperkeratosis in a 51-year-old male with metastatic SCC of the esophagus. This figure has been reproduced with permission of Elsevier (Viteri et al. [29]). SCC, squamous cell carcinoma.

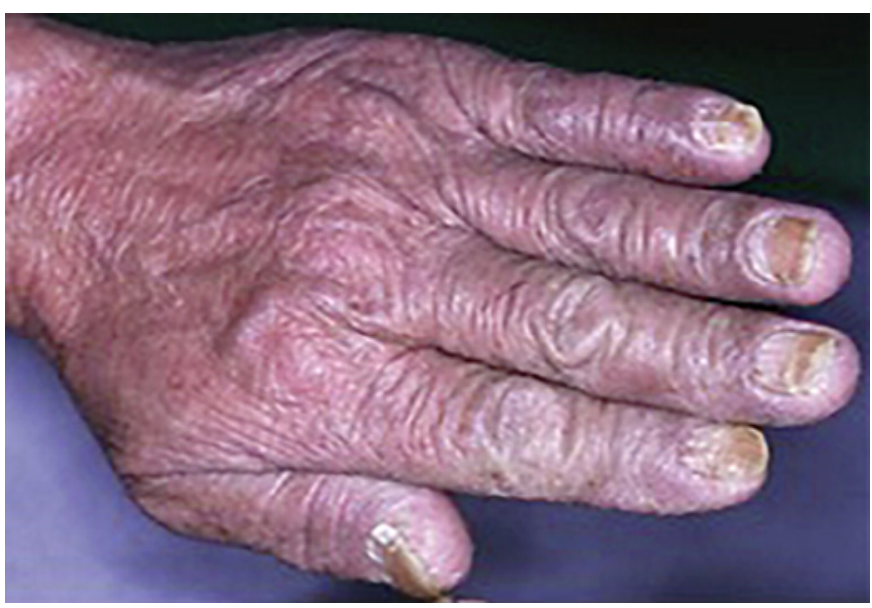

Fig. 2. Acrokeratosis paraneoplastica. Nail plate thickening and yellow and brown discoloration of all fingernails and toenails in a 75 -year-old male with hepatocellular carcinoma. This figure has been reproduced with permission of John Wiley and Sons (Goto et al. [39]).

and thymic carcinomas were also reported as primary malignancies. Approximately $8 \%$ of the cases involved carcinomas were of indeterminate origin (Table 2). Metastases were present in 22 cases (46\%), not present in 12 cases (25\%), and not specified in 14 (29\%) cases.

Nail changes in acrokeratosis paraneoplastica patients were nonspecific and varied (Table 3 ). The most common nail findings were nail plate thickening (35\%), subungual hyperkeratosis $(31 \%)$, yellow/brown nail plate discoloration (27\%), onycholysis (27\%), longitudinal ridging 
(25\%), and loss or destruction of the nail plate (13\%) (Fig. 1, 2). Paronychia was seen in $6 \%$ of the cases, often causing pain. Many patients had 2 or more nail findings concurrently; nail plate thickening and subungual hyperkeratosis were most common. Approximately, $79 \%$ of the patients had nail findings prior to cancer diagnosis, with onychodystrophies on average presenting in the preceding 10 months. In about $10 \%$ of the patients, nail changes occurred following malignancy diagnosis with an average of 14 months post-diagnosis. Nail findings presented concurrently with the diagnosis of cancer in about $6 \%$ of the cases, and the timing of nail findings were not specified in $5 \%$ of the cases. The majority of fingernails and toenails were involved in all cases except for one in which the onychodystrophy was limited to one fingernail.

\section{Discussion}

In our review of 48 cases of acrokeratosis paraneoplastica with nail findings, 36 patients (75\%) were males, with a mean age of 62.5 years, and the majority of patients were either Caucasian or White (23\%). The majority of patients were of Fitzpatrick skin type I-II (31\%), followed by skin type III-IV (27\%), and skin type V-VI (23\%). Our findings are consistent with those of Bolognia et al. [1], who reviewed 93 cases of acrokeratosis paraneoplastica (with and without nails findings) and reported that $89 / 93$ patients were males (96\%) with a mean age of $60 \pm 8.5$ years. In a more recent review on Bazex syndrome (not nail specific) by Räßler et al. [6], 54/70 (77\%) patients were males, with mean ages of 65 and 62 years for patients with nail findings and no nail findings, respectively .

In our study of Bazex patients with nail findings, malignancies were most commonly localized to the head and neck (44\%), followed by the lung (21\%), and gastrointestinal tract (12\%). In addition, metastatic anaplastic tumors and SCCs of unknown primary origins accounted for $8 \%$ of the cases. Other types of carcinomas in our review included cervical SCC, transitional-cell carcinoma of the bladder, lobular carcinoma of the breast, liposarcoma, cutaneous SCCs, and thymic carcinoma. SCCs of the head and neck were also the most commonly reported underlying malignancies in Bazex syndrome, in patients with and without nail findings, in prior reviews. Bolognia et al. [1] reported that 57/93 patients (61\%) had SCC of the esophagus, larynx, or pharynx. Other common sites included the lung and the gastrointestinal tract. Räßler et al. [6] reported that $11 / 77$ patients (14\%) had a primary malignancy of the lung, 8/77 patients (11\%) had adeno- carcinoma of the gastrointestinal tract, and 6/77 cases (8\%) had metastatic anaplastic tumors of unknown origins with lymph node metastases of occult carcinomas. There was a case of T-cell lymphoma [7] and a neuroendocrine tumor [8] in patients with acrokeratosis paraneoplastica; however, those patients did not present with any nail changes.

We found that nail changes presented at an average of 10 months prior to malignancy diagnosis for $79 \%$ of the Bazex patients. In 2 cases, nail changes presented simultaneously with carcinoma recurrence $[9,10]$. Our nail data are consistent with those of Bolognia et al. [1], who reported that in $63 \%$ of the Bazex patients, cutaneous manifestations preceded the diagnosis of malignancy, at an average time of 11 months. Nail findings typically appeared concurrently with the initial cutaneous manifestations; Bazex and Griffiths [4] described the cutaneous presentation of acrokeratosis paraneoplastica occurring in 3 stages. In the first stage, papulosquamous plaques present on the distal digits, nose, and ears, along with nail dystrophy $[1,4]$. In the second stage, the papulosquamous plaques extend to the cheeks, palms, and soles. In the third stage, typically when metastases occur, the plaques spread to the elbows, knees, and dorsae of the hands and feet [1].

In our review, the most common nail changes were nail plate thickening, subungual hyperkeratosis, yellow or brown nail plate discoloration, onycholysis, longitudinal ridging, and loss or destruction of nail plate. Presentation with 2 or more nail changes simultaneously was frequent. Paronychia, while less common than some of the other nail findings, is an important source of morbidity in these patients. Bolognia et al. [1] reported on similar nail findings associated with acrokeratosis paraneoplastica as in our study; less common nail changes were macerated nails, atrophy, slow growth, and nail plate loss.

Our review is subject to several limitations. Due to the rarity of Bazex Syndrome, there were only 48 cases with associated nail findings published. In some case reports, photograph quality was insufficient to characterize specific nail changes, and/or detailed descriptions of nail findings and digits affected were lacking. Patient demographics were not reported in some cases, and Fitzpatrick skin types were not discernible for others.

A broad variety of nail findings are associated with acrokeratosis paraneoplastica, with many patients presenting with more than one type of onychodystrophy. The changes often affected most or all nails and presented concurrently with cutaneous findings. No nail changes were diagnostic or specific. The presence of subungual 
hyperkeratosis, onycholysis, nail plate thickening, longitudinal ridging, onychomadesis, yellow or brown nail plate discoloration, paronychia, nail plate loss and less common changes such as horizontal ridging, onychomycosis, atrophy, clubbing, pitting, and fissuring involving most or all nails should raise suspicion for acrokeratosis paraneoplastica, especially accompanied by the characteristic cutaneous lesions. When a patient presents with papulosquamous plaques on the skin accompanied by nail dystrophy, psoriasis is an important diagnostic consideration. Nail clippings and/or cultures may be performed to rule out other nail conditions in the differential diagnosis, such as onychomycosis or nail psoriasis. In the absence of hyphae, infiltration of neutrophils, and subungual hyperkeratosis in nail plate clippings, dermatologists should be prompted to perform a thorough review of systems, physical examination with palpation of lymph nodes, and referral to primary care for age appropriate malignancy screening and further testing if dictated by physical findings. Since nail changes typically present almost a year prior to diagnosis of malignancy, careful examination of the nails, hands, and digits and appropriate malignancy workup may be lifesaving. In addition, nail alterations in patients with acrokeratosis paraneoplastica should be monitored closely, since onychodystrophies may present during disease recurrence.

\section{Conflict of Interest Statement}

The authors have no conflict of interest to declare. This manuscript was not funded. This work has not been previously presented and is not under consideration at any other journal. No reprints requested.

\section{Funding Sources}

The authors did not receive any funding.

\section{Author Contributions}

Ms. Bipasha Roy has contributed to the conception and design of the work, acquisition, analysis, and interpretation of the data. Bipasha Roy has contributed to drafting the work and revising it critically, has been involved in the final approval of the version to be published, and agrees to be accountable for all aspects of the work in ensuring that questions related to accuracy or integrity of any part of the work are appropriately investigated and resolved.

Dr. Shari Lipner has contributed to the conception and design of the work, acquisition, analysis, and interpretation of the data. Dr. Shari Lipner has contributed to drafting the work and revising it critically, has been involved in the final approval of the version to be published, and agrees to be accountable for all aspects of the work in ensuring that questions related to accuracy or integrity of any part of the work are appropriately investigated and resolved.

\section{References}

1 Bolognia JL, Brewer YP, Cooper DL. Bazex syndrome (acrokeratosis paraneoplastica). An analytic review. Medicine. 1991;70(4): $269-80$.

2 Sharma V, Sharma NL, Ranjan N, Tegta GR, Sarin S. Acrokeratosis paraneoplastica (Bazex syndrome): case report and review of literature. Dermatol Online J. 2006 Jan 27;12(1):11.

3 Khachemoune A, Yalamanchili R, Rodriguez C. Bazex syndrome (paraneoplastic acrokeratosis). Cutis. 2004;74(5):289-92.

4 Bazex A, Griffiths A. Acrokeratosis paraneoplastica: a new cutaneous marker of malignancy. Br J Dermatol. 1980;103(3):301-6.

5 Oakley A. Fitzpatrick skin phototype. DermNetzNZ. 2012.

6 Räßler F, Goetze S, Elsner P. Acrokeratosis paraneoplastica (Bazex syndrome): a systematic review on risk factors, diagnosis, prognosis and management. J Eur Acad Dermatol Venereol. 2017;31:1119-36.

7 Lin YC, Chu CY, Chiu HC. Acrokeratosis paraneoplastica (Bazex's syndrome): unusual association with a peripheral T凶cell lymphoma. Acta Derm Venereol. 2001;81:440-1.
8 Halpern SM, O’Donnell LJ, Makunura CN. Acrokeratosis paraneoplastica of Bazex in association with a metastatic neuroendocrine tumour. J R Soc Med. 1995;88(6):353p-4p.

9 O'Brien TJ. Bazex syndrome (acrokeratosis paraneoplastica). Australas J Dermatol. 1995; 36(2):91-3.

10 Taher M, Grewal P, Gunn B, Tonkin K, Lauzon G. Acrokeratosis paraneoplastica (Bazex syndrome) presenting in a patient with metastatic breast carcinoma: possible etiologic role of zinc. J Cutan Med Surg. 2007;11(2):78-83.

11 Jacobsen FK, Abildtrup N, Laursen SO, Brandrup F, Jensen NK. Acrokeratosis paraneoplastica (Bazex' syndrome). Arch Dermatol. 1984;120(4):502-4.

12 Richard M, Giroux JM. Acrokeratosis paraneoplastica (Bazex' syndrome). J Am Acad Dermatol. 1987;16(1 Pt 2):178-83.

13 Douglas WS, Bilsland DJ, Howatson R. Acrokeratosis paraneoplastica of Bazex: a case in the UK. Clin Exp Dermatol. 1991;16(4):2979.

14 Handfield-Jones SE, Matthews CN, Ellis JP, Das KB, McGibbon DH. Acrokeratosis paraneoplastica of Bazex. J R Soc Med. 1992;85(9): $548-50$.
15 Mounsey R, Brown DH. Bazex syndrome. Otolaryngol Head Neck Surg. 1992;107(3): 475-7.

16 Poskitt BL, Duffill MB. Acrokeratosis paraneoplastica of Bazex presenting with carpal tunnel syndrome. Br J Dermatol. 1992;127(5): 544-5.

17 Arregui MA, Ratón JA, Landa N, Izu R, Eizaquirre X, Díaz-Pérez JL. Bazex’s syndrome (acrokeratosis paraneoplastica)-first case report of association with a bladder carcinoma. Clin Exp Dermatol. 1993;18(5):445-8.

18 Hara M, Hunayama M, Aiba S, Suetake T, Watanabe M, Tanaka M, et al. Acrokeratosis paraneoplastica (Bazex syndrome) associated with primary cutaneous squamous cell carcinoma of the lower leg, vitiligo and alopecia areata. Br J Dermatol. 1995;133(1):121-4.

19 Laccourreye O, Laccourreye L, Jouffre V, Brasnu D. Bazex's acrokeratosis paraneoplastica. Ann Otol Rhinol Laryngol. 1996;105(6): 487-9.

20 Wareing MJ, Vaughan-Jones SA, McGibbon DH. Acrokeratosis paraneoplastica: Bazex syndrome. J Laryngol Otol. 1996;110(9):899900 
21 Sarkar B, Knecht R, Sarkar C, Weidauer H. Bazex syndrome (acrokeratosis paraneoplastica). Eur Arch Otorhinolaryngol. 1998; 255(4):205-10.

22 Mutasim DF, Meiri G. Bazex syndrome mimicking a primary autoimmune bullous disorder. J Am Acad Dermatol. 1999;40(5 Pt 2): 822-5.

23 Hsu YS, Lien GS, Lai HH, Cheng YS, Hu CH, Hsieh MC, et al. Acrokeratosis paraneoplastica (Bazex syndrome) with adenocarcinoma of the colon: report of a case and review of the literature. J Gastroenterol. 2000;35(6):460-4.

24 Buxtorf K, Hübscher E, Panizzon R. Bazex syndrome. Dermatology. 2001;202(4):350-2.

25 Gill D, Fergin P, Kelly J. Bullous lesions in Bazex syndrome and successful treatment with oral psoralen phototherapy. Australas J Dermatol. 2001;42(4):278-80.

26 Chave TA, Bamford WM, Harman KE. Acrokeratosis paraneoplastica associated with recurrent metastatic thymic carcinoma. Clin Exp Dermatol. 2004;29(4):430-2.

27 Rao R, Shenoi SD. Acrokeratosis paraneoplastica (Bazex syndrome): an atypical presentation. Dermatol Online J. 2004;10(1):21.

28 Valdivielso M, Longo I, Suárez R, Huerta M, Lázaro P. Acrokeratosis paraneoplastica: Bazex syndrome. J Eur Acad Dermatol Venereol. 2005;19(3):340-4.

29 Viteri A, Muñoz A, Barcelò R. Acrokeratosis paraneoplastica (Bazex syndrome) preceeding the diagnosis of metastatic squamous cell carcinoma of the esophagus. J Am Acad Dermatol. 2005;52(4):711-2.

30 Karabulut AA, Sahin S, Sahin M, Ekșioğlu M, Ustün H. Paraneoplastic acrokeratosis of Bazex (Bazex's syndrome): report of a female case associated with cholangiocarcinoma and review of the published work. J Dermatol. 2006;33(12):850-4.

31 Sator PG, Breier F, Gschnait F. Acrokeratosis paraneoplastica (Bazex's syndrome): association with liposarcoma. J Am Acad Dermatol. 2006;55(6):1103-5.
32 Strobel ES, Bouveret C, Kohl PK. Acrokeratosis paraneoplastica of Bazex as an indicator for underlying squamous cell carcinoma of the lung. J Cancer Res Clin Oncol. 2006; 132(6):376-8

33 Poligone B, Christensen SR, Lazova R, Heald PW. Bazex syndrome (acrokeratosis paraneoplastica). Lancet. 2007;369(9560):530.

34 Baek JO, Lee HY, Lee JR, Roh JY. Acrokeratosis Paraneoplastica with adenocarcinoma of the colon treated with topical tretinoin. Ann Dermatol. 2008;20(4):216-20.

35 Medenica L, Gajić-Veljić M, Skiljević D, Pesko P. Acrokeratosis paraneoplastica Bazex syndrome associated with esophageal squamocellular carcinoma. Vojnosanit Pregl. 2008;65(6):485-7.

36 Crucitti A, Feliciani C, Grossi U, La Greca A, Porziella V, Giustacchini P, et al. Paraneoplastic acrokeratosis (Bazex syndrome) in lung cancer. J Clin Oncol. 2009;27(36):e2668.

37 Medenica L, Gajić-Veljić M, Skiljević D, Pesko P. Acrokeratosis paraneoplastica Bazex syndrome associated with esophageal squamocellular carcinoma. Vojnosanit Pregl. 2008;65(6):485-7.

38 Santos-Silva AR, Correa MB, Vargas PA, Almeida OP, Lopes MA. Bazex syndrome (acrokeratosis paraneoplastica) diagnosed in a patient with oral persistent ulcerations. Head Neck Pathol. 2010;4(4):312-7.

39 Goto H, Hara H, Takayanagi T, Terui T. Coexistence of papuloerythroderma of Ofuji and acrokeratosis paraneoplastica (Bazex syndrome) preceding the diagnosis of primary hepatocellular carcinoma. Int J Dermatol. 2011;50(11):1393-6.

40 Zarzour JG, Singh S, Andea A, Cafardi JA. Acrokeratosis paraneoplastica (Bazex syndrome): report of a case associated with small cell lung carcinoma and review of the literature. J Radiol Case Rep. 2011;5(7):1-6.
41 Rodrigues IA Jr, Gresta LT, Cruz RC, Carvalho GG, Moreira MH. Bazex syndrome. An Bras Dermatol. 2013;88(6 Suppl 1):209-11.

42 Fleming JD, Stefanato CM, Attard NR. Bazex syndrome (acrokeratosis paraneoplastica). Clin Exp Dermatol. 2014;39(8):955-6.

43 Graves MS, Hardin ME, Davis LS. A case of bazex syndrome with genital involvement. JAMA Dermatol. 2014;150(12):1368-70.

44 Robert M, Gilabert M, Rahal S, Ries P, Raoul JL. Bazex syndrome revealing a gastric cancer. Case Rep Oncol. 2014;7(1):285-7.

45 Amano M, Hanafusa T, Chikazawa S, Ueno $\mathrm{M}$, Namiki T, Igawa $\mathrm{K}$, et al. Bazex syndrome in lung squamous cell carcinoma: high expression of epidermal growth factor receptor in lesional keratinocytes with Th2 immune shift. Case Rep Dermatol. 2016;8(3):358-62.

46 Squires B, Daveluy SD, Joiner MC, Hurst N, Bishop M, Miller SR. Acrokeratosis paraneoplastica associated with cervical squamous cell carcinoma. Case Rep Dermatol Med. 2016;2016:7137691.

47 Vatandoust S, McKay BP, McLeay W, Miliauskas J, Gordon L, Wesley JA, et al. Acrokeratosis paraneoplastica (Bazex syndrome) associated with metastatic cutaneous squamous cell carcinoma. Intern Med J. 2016; 46(1):119-20.

48 Zhao J, Zhang X, Chen Z, Wu JH. Case report: Bazex syndrome associated with pulmonary adenocarcinoma. Medicine. 2016;95(2): e2415.

49 Shikino K, Ikusaka M. Bazex syndrome. CMAJ. 2017;189(17):E639.

50 Adelman ML, Ho QA, Agrawal A. Bazex syndrome in a patient with head and neck malignancy. JAAPA. 2018;31(6):30-3.

51 Dabas G, De D, Handa S, Chatterjee D, Radotra BD. Acrokeratosis paraneoplastica (Bazex syndrome). QJM. 2018;111(1):63-4.

52 Mititelu R, Powell M. A case report of resolution of acrokeratosis paraneoplastica (Bazex syndrome) post resection of non-small-cell lung carcinoma. SAGE Open Med Case Rep. 2019;7:2050313X19881595. 